\title{
Antibiotic Resistance Analysis of Vibrio spp Isolated from Different Types of Water Sources of Bangladesh and Their Characterization
}

\author{
Milon Kumar Das Sarker', Tanvir Ahammed², Md. Sahabuddin ${ }^{3}$, Pinki Akter ${ }^{1}$, Azizul Haque ${ }^{4}$, Md. Rajib \\ Hossain $^{5}$, Md. Golam Mosaib ${ }^{6}$, Md. Robiul Islam ${ }^{7}$, Goutom Chandra Mondol ${ }^{8 *}$, and Md. Firoz Alam ${ }^{9}$ \\ ${ }^{1}$ Dept. of Microbiology, Stamford University Bangladesh, Bangladesh; ${ }^{2}$ Dept. of Microbiology and Hygiene, Bangladesh \\ Agricultural University, Bangladesh; ${ }^{3}$ Dept. of Biotechnology and Genetic Engineering, BSMRSTU, Bangladesh; ${ }^{4}$ Dept. of \\ Microbiology, University of Chittagong, Bangladesh; ${ }^{5}$ Dept. of Environmental Science \& Disaster Management, BSMRSTU, \\ Bangladesh; ${ }^{6}$ Dept. of Biochemistry and Molecular Biology, Gono Bishwabidyalay, Bangladesh; ${ }^{7}$ Dept. of Microbiology, \\ Jagannath University, Bangladesh; ${ }^{8}$ Department of Public Health, ASA University, Bangladesh, and ${ }^{9}$ Dept. of Biotechnology \\ and Genetic Engineering, Islamic University, Bangladesh
}

*Correspondence: goutommicro@gmail.com

\begin{abstract}
Cholera is an acute type of the diarrheal disease that torments human civilization over the centuries. The wickedness of human sufferings led physicians, and researchers to carry out extensive research on cholera and Vibrio cholerae leading to potential discoveries that opened up new areas of research or new disciplines in biomedical sciences. An attempt is made here to summarize some of these breakthroughs and outline their significance in broader perspectives. In the present study, a total of 12 samples were collected from four types of water sources for separation of Vibrio spp. Water samples are enrichment into alkaline peptone water then inoculate into culture media such as Nutrient agar, MacConkey, and Thiosulfate Citrate Bile Salts Sucrose (TCBS) agar medium. After incubation of TCBS plates for $24 \mathrm{~h}$ at $37^{\circ} \mathrm{C}$ yellow and green colonies are screened out for biochemical identification. No-sucrose fermenting Vibrio parahaemolyticus, Vibrio mimicus, and Vibrio vulnificus show green colonies and sucrose fermenting Vibrio cholerae and Vibrio alginolyticus shows yellow colonies on TCBS. To identify the Vibrio spp extracts biochemical test was carried out and typical Vibrio spp give a positive result. The majority of Vibrio spp are avirulent, but certain strains may be sporadically human pathogenic. The antibiotic resistance studies represented that among the 9 extracts were resistant against Erythromycin, Penicillin, Cephalexin, Vancomycin and 4 extracts resistant against Tetracycline. To expand present knowledge of the occurrence, ecological niche and persistence of significant human pathogenic Vibrio spp in water environments, occurrence, and laboratory studies were tested.
\end{abstract}

Keywords: Isolation, Vibrio cholera, Water sources, Pathogenic, Diarrhea, and Identification.

\section{INTRODUCTION}

Water is the necessity for life and an adequate, safe and accessible supply is of paramount importance. Life is possible on earth due to the presence of water. The impact of water on health is associated with unwholesome sources contaminated with faces containing pathogenic microorganisms. The quality of drinking water is closely associated with human health and providing safe drinking water is a major public health priority. It is the dispersion medium for all biochemical reactions of the living process and takes part in many of these reactions. Freshwater bodies 
serve as the main water resources in rural areas used for drinking, cooking, and irrigation for agriculture in most communities that have little or no access to potable, safe water. $V$. cholerae is known to be normal inhabitants of surface water. Illnesses in humans occur after ingestion or direct wound contact with contaminated food or water (Cho et al., 2008; Turner et al., 2013). At least twelve Vibrio species are of clinical significance for the human, being $V$. cholerae, $V$. parahaemolyticus and $V$. vulnificus the three main species (Gomez-Gil et al., 2014).

Over the years, several researchers have focused on the sternness of diseases caused by $V$. cholerae leaving out relatively minor Vibrio species of medical interest, some of which are described as emerging pathogens able to cause mild to severe human diseases. Vibrio spp has emerged as a serious threat to human health worldwide. The growing number and severity of food poisoning incidents around the world have greatly increased public awareness about food safety (Forsythe, 2000). Many Vibrio species are pathogens to human and have been implicated in foodborne disease. Five types of diseases such as tail necrosis, shell disease, red disease, loose shell syndrome (LSS) and white gut disease (WGD) is caused by Vibrio spp in Penaeus monodon (Jayasree et al., 2006). Vibrio spp has also been implicated in mortality events in the wild (Li et al., 2006). Pathogenic Vibrio causes acute gastroenteritis characterized by diarrhea, headache, vomiting, nausea, and fever (Yang, et al., 2008). V. anguillarum, $V$. harveyi, $V$. alginolyticus, $V$. parahaemolyticus, and $V$. vulnificus is among the wellknown fish pathogen worldwide (Haenen et al., 2014; Azila et al., 2017; Ina-Salwany et al., 2018).

Vibrio spp is rod-shaped Gram-negative bacteria that are widespread in coastal and estuarine environments around the world. $V$. cholerae is a usual inhabitant of the environment and causes severe diarrheal disease contaminating thousands of people each year in developing countries. V. parahaemolyticus was first identified as a foodborne pathogen in the 1950s, and, in subsequent decades, became globally recognized as an etiological agent of diarrheal disease associated with seafood consumption (Parveen et al., 2008).
Vibrio is a Gram-negative halophilic bacterium found abundantly in marine and estuarine environments (Thompson et al., 2004; Raissy et al., 2014). Among the different species, $V$. parahaemolyticus has emerged as a significant pathogen for $M$. rosenbergii (Khuntia et al., 2008). The genus Vibrio includes some species that behave as opportunistic pathogens and can be involved both in cultured gilthead sea bream outbreaks and in cases of human disease (Austin and Zhang, 2006). Typical symptoms of the gastroenteritis may include abdominal pain, diarrhea, nausea, and fever (Tan et al., 2017).

Bacteria can have an impact on the quality of water by controlling the amount of oxygen and other elements and by causing diseases in aquatic organisms and humans. Antibiotic-resistant bacteria may represent a potential threat to human health due to direct transmission through the food chain (Duran and Marshall, 2005; Rahman et al., 2019) or by transferring the acquired antimicrobial resistance to human pathogens by mobile genetic elements (Guglielmetti et al., 2009). Vibrio spp usually, are said to be highly susceptible to most clinically used antibiotics (Mala et al., 2014; Shaw et al., 2014). The number of Vibrio spp. classified as pathogenic strains are at least 11 , including $V$. cholerae as the main cause of diarrhea, $V$. parahaemolyticus as the cause of foodborne gastroenteritis (Ozer, et al., 2008). The aim of this study was to identify, characterize, and determine antibiotic resistance of Vibrio species of clinical importance in water samples and determine their pathogenicity, which will help to control Vibrioassociated gastroenteritis from Bangladesh.

\section{MATERIALS AND METHODS}

2.1 Sample Collection and Cultural - The present work was divided by separation and Identification of Vibrio spp from different types of water sources. The sample was collected from different region like as beside the Niribili area, Savar and Megna River from Daudkandi, Comilla, Bangladesh. For the separation of bacteria the enrichment, streak and spread plate approachs were followed by alkaline peptone water, Nutrient agar MacConkey's agar and TCBS agar were used for the isolation purpose. 
Table 1: Water was collected from different region.

\begin{tabular}{|c|c|c|c|c|}
\hline $\begin{array}{c}\text { Sample } \\
\text { No. }\end{array}$ & Sampling source & Sample collection area & Sampling Time & Total sample No. \\
\hline 1 & Tap water & \multirow{4}{*}{$\begin{array}{l}\text { Hostel, } \\
\text { Niribili area, } \\
\text { Daudkandi }\end{array}$} & \multirow{4}{*}{3} & \multirow{4}{*}{12} \\
\hline 2 & Pond water & & & \\
\hline 3 & River water & & & \\
\hline 4 & Sewage water & & & \\
\hline
\end{tabular}

2.2 Enrichment in Alkaline Peptone Water (APW) Vibrio spp grows very rapidly in APW and at 6 to 8 hours will be present in greater numbers than nonVibrio organisms. Enrichment in APW enhances the separation of $V$. cholerae when few organisms are present, as in specimens from convalescent patients and asymptomatic carriers. An enrichment medium containing a selective agent may not offer any advantage over APW if it is used with short incubation time (6 to 8 hours).

\subsection{Nutrient and Mac Monkeys Agar- Nutrient agar} was used for cultivating of non-fastidious microorganisms. A differential medium was also used for the separation of Coliforms and intestinal pathogens in water and biological specimens.

2.4 TCBS Agar - TCBS is the medium of choice for the separation of $V$. cholerae and is widely used worldwide, it has a relatively short shelf life once prepared (3 to 5 days) unless plates are carefully protected against drying. TCBS agar is green when prepared. Overnight growth (18 to 24 hours) of $V$. cholerae will produce large ( 2 to $4 \mathrm{~mm}$ in diameter), slightly flattened, yellow colonies with opaque centers.

\subsection{Morphological Characterization by Gram's}

Staining - The most widely used staining procedure in microbiology is the gram stain. The procedure is based on the ability of microorganisms to retain the color of the stains used during the gram stain reaction.

Gram-negative bacteria are decolorized by the alcohol, losing the color of the primary stain, purple. Grampositive bacteria are not decolorized by alcohol and will remain as purple. After decolonization step and a counter stain is used to impart a pink color to the decolorized gram-negative organisms.

\subsection{Biochemical Test for the Identification of the} Organism: The biochemical identification of the organism was done by performing the biochemical tests. The biochemical tests were done as stated on Berge's Manual of Determinative Bacteriology.

Several types of biochemical tests were performed in this study such as Sugar Fermentation Test, Oxidase Test, Catalase Test, Indole Test, Methyl Red-Catalase Test (MR-VP), Triple Sugar Iron Agar (TSI), Simmons Citrate Agar (SCA), Urea Test, Kligler Iron agar (KIA) Test and Gelatin Hydrolysis Test, Starch Hydrolysis Test, etc

2.7 Preparation of a Hanging Drop Slide - A hanging drop slide allows viewing live bacteria under a microscope. This approach allows for maintaining their natural shape and makes it possible to observe their behavior. If an organism is motile, its activity is clearly apparent, and directional, place locomotion will be observed. This test was performed according to the approach described by Cowan to differentiate motile bacteria from non-motile one.

2.8 Antibiotic Sensitivity Test - The list of commercially available antimicrobial disc used in this study with their concentration is given bellow After placing of the disc on the plate, the plates were inverted and incubated at $37^{\circ} \mathrm{c}$ for 16 to 18 hours after incubation, the diameter of the zones of complete inhibition (including the diameter of the disc) was measured and recorded in millimeters. The measurements were made with a ruler on the undersurface of the plate without opening the lid. 
Table 2: Different antimicrobial agents with their disc concentration for Antibiotic sensitivity test.

\begin{tabular}{|lcc|}
\multicolumn{1}{c}{ Antimicrobial agents } & Symbol & Disc concentration (ug/disc) \\
\hline Erythromycin & E & 15 \\
\hline Tetracycline & TE & 30 \\
\hline Chloramphenicol & C & 30 \\
\hline Gentamycin & GEN & 10 \\
\hline Ciprofloxacin & CIP & 5 \\
\hline Vancomycin & VA & 30 \\
\hline Nitrofurantoin & F & 300 \\
\hline Penicillin & P & 10 \\
\hline Sulphamethoxazole & SXT & 25 \\
\hline Cephalexin & CN & 30 \\
\hline
\end{tabular}

\section{RESULTS AND DISCUSSION}

\subsection{Separation and study of cultural characters: In} the present study, 12 water samples were collected from different sources such as tap water, pond water, river water and sewage water for isolation and identification of Vibrio spp gram negative bacteria. All samples should be tested before enrichment and after enrichment. Before enrichment samples were inoculated into culture media such as Nutrient agar, MacConkey's and TCBS agar used for separation of Vibrio spp. After enrichment into alkaline peptone water can be used to enhance the recovery of Vibrio spp where there are few organisms present. In the present study, specific biochemical tests were used for the detection of Gram-negative bacteria.
3.2 Nutrient, Mac Conkey, and TCBS Agar: Nutrient agar represented circular, smooth and translucent colonies. MacConkey agar represented colorless colonies after prolonged incubation pink color colonies were seen. This is a highly selective medium which is used to extract and to differentiate the sucrose fermenting from non-sucrose fermenting species of Vibrio. TCBS agar represented that large 2 to $3 \mathrm{~mm}$, smooth, yellow, shiny, convex and slightly flattened with opaque centers. Among the 12 samples, 2 samples did not show any growth of an organism in the media. Ten-fold dilutions of water samples were made down to $10-8$, before $0.1 \mathrm{ml}$ of the aliquot of each serial dilution was plated onto TCBS agar in triplicate (Letchumanan et al. 2015).
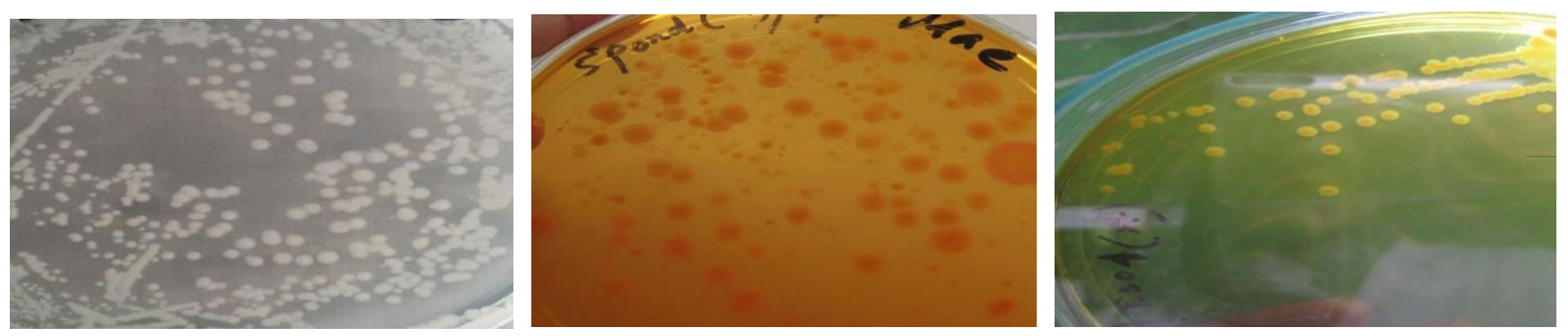

Fig 1: Culture of organism on Nutrient 's Agar (Left), Culture of organism on MacConkey Agar (Middle), and Culture of organism on TCBS agar (right).

\subsection{Cultural Characteristic on TCBS Agar - Among} the 15 extracts, 9 isolates represented green colony and 6 extracts represented yellow colony. Initial bacterial separations were made from the hemolymph of infected moribund animals using TCBS agar plates (Zhou et al., 2012). 12 samples were collected from different region for separation and identification of
Vibrio spp in this present investigation. We extracted 2 types of Vibrio spp colony such as yellow and green colony. Yellow colonies of Sucrose fermenting Vibrio like $V$. cholera and $V$. alginolyticus. Green colonies of non-sucrose fermenting Vibrio like $V$. parahaemolyticus, and V. mimicus. 
Table 3: Different extracts of Vibrio spp with their various color of colony in the growth media.

\begin{tabular}{|c|c|}
\hline Sample no & Color of colony \\
\hline $\mathbf{1}$ & Yellow, Green \\
$\mathbf{2}$ & Green \\
$\mathbf{3}$ & Green \\
$\mathbf{4}$ & Large yellow, Green \\
$\mathbf{5}$ & Green, yellow \\
$\mathbf{6}$ & Yellow \\
$\mathbf{7}$ & Green \\
$\mathbf{8}$ & Yellow, Green \\
$\mathbf{9}$ & Yellow, Green \\
$\mathbf{1 0}$ & Green \\
\hline
\end{tabular}

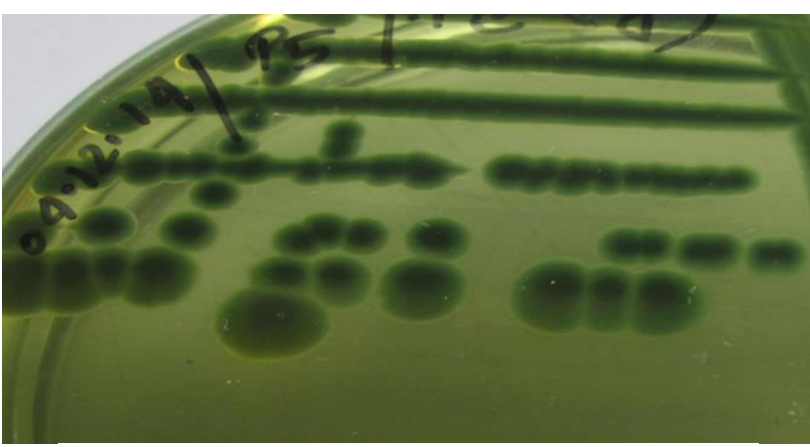

Fig 2: Blue green colonies of non sucrose fermenting Vibrio on TCBS agar.

bacteria with the single polar flagellum. We worked with 15 extracts of 12 samples of water after 3 times of sampling we get 15 extracts from 4 sources of water such as tap water, pond water, river water, and sewage water. Among 15 extracts, 8 extracts of 4 samples represented a zone of inhibition on blood agar media. The motile and non-motile organisms were identified by observing motility.
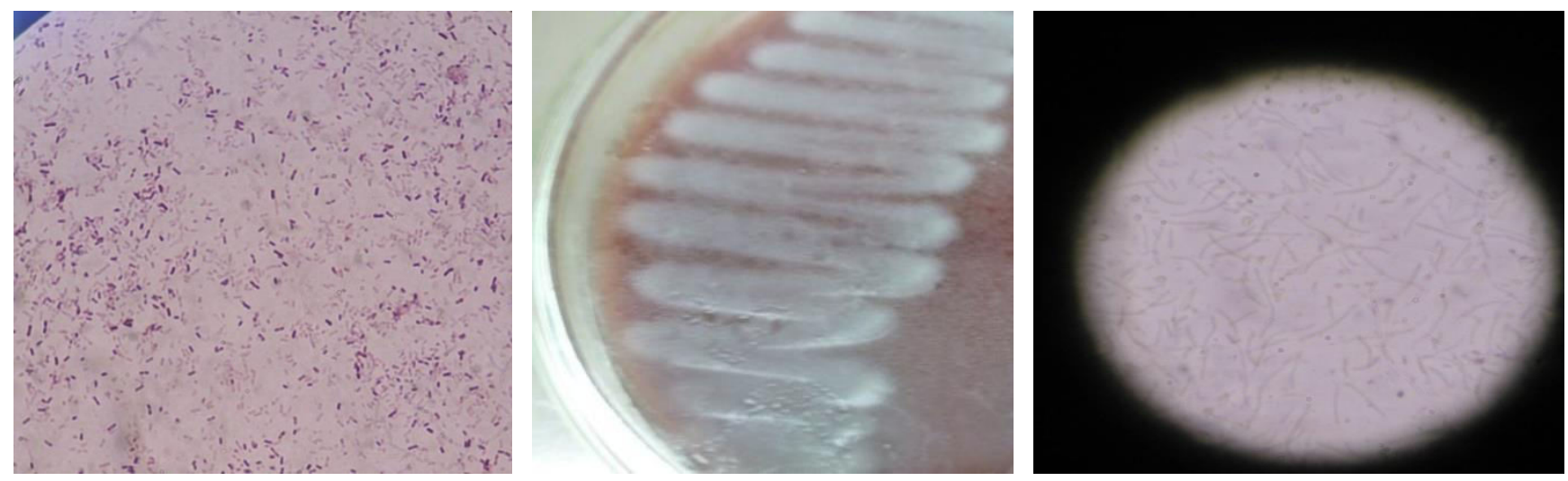

Fig 3: Morphology of Vibrio spp under light microscopy (left); Growth on Blood agar (right) and Hanging drop slide examined fewer than 40x power microscope.

Table 4: Haemolytic activity of Vibrio spp in the Blood agar.

\begin{tabular}{|cccc|}
\hline Isolate no & Blood Agar & Isolate no & Blood Agar \\
\hline $\mathbf{1}$ & $\beta$-haemolytic & 6 & $\alpha$-haemolytic \\
\hline $\mathbf{2}$ & $\beta$-haemolytic & 7 & $\alpha$-haemolytic \\
\hline $\mathbf{3}$ & $\beta$-haemolytic & 8 & $\alpha$-haemolytic \\
\hline $\mathbf{4}$ & No haemolytic & 9 & $\alpha$-haemolytic \\
\hline $\mathbf{5}$ & No haemolytic & 10 & No haemolytic \\
\hline
\end{tabular}


3.5 Biochemical Characteristics of the Extracts - All the isolates were tested for selective biochemical tests which are presented in Table 5. Among 12 samples of 15 extracts, 15 extracts represented oxidase-positive. Among 15 extracts, 15 extracts represented catalasepositive. Among 15 extracts, 15 extracts represented oxidase and catalase positive.

Among the 15 extracts of 12 samples MIO represented a positive result, 15 extracts represented urease negative, a yellow colony of Vibrio spp represented starch positive and green colonies represented starch hydrolysis negative, Among 7 extracts 2 extracts represented citrate negative, 1 extract represented indole positive, 3 extracts represented indole negative. Among the 4 extracts, 2 extracts MR positive, 2 negative. 15 extracts of 2 sample VP positive result. Sugar fermentation test of Vibrio spp fermented dextrose, sucrose and Mannitol produce acid and gas but did not ferment lactose. 7 extracts, 6 extracts of 12 samples represented positive KIA test. Among 15 extracts of 12 samples represented small, curved, rods with darting motility of wet mount test.

Table 5: Enrichment results of the representative test extracts.

\begin{tabular}{|c|c|c|c|c|c|c|c|c|}
\hline \multirow{2}{*}{$\begin{array}{l}\text { Isolate } \\
\text { name }\end{array}$} & \multicolumn{4}{|c|}{ KIA } & \multirow[t]{2}{*}{ MIO } & \multirow{2}{*}{$\begin{array}{l}\text { Urease } \\
\text { test }\end{array}$} & \multirow{2}{*}{$\begin{array}{l}\text { Citrate } \\
\text { utilization }\end{array}$} & \multirow{2}{*}{ TSI } \\
\hline & Slant & Butt & $\begin{array}{l}\text { Gas } \\
\text { production }\end{array}$ & $\mathbf{H}_{2} \mathrm{~S}$ & & & & \\
\hline 1 & Red & Yellow & + & - & + & - & + & - \\
\hline 2 & Red & Yellow & + & - & + & - & + & + \\
\hline 3 & Red & Yellow & + & - & + & - & + & - \\
\hline 4 & Red & Yellow & + & + & + & - & + & - \\
\hline 5 & Red & Yellow & + & + & + & - & + & - \\
\hline 6 & Yellow & Yellow & + & + & + & - & - & - \\
\hline 7 & Red & Red & - & - & + & - & - & - \\
\hline 8 & Red & Yellow & + & + & + & - & - & - \\
\hline 9 & Red & Yellow & + & + & + & - & + & - \\
\hline 10 & Red & Yellow & + & + & + & - & + & - \\
\hline
\end{tabular}

Symbols: +: positive and -: negative g: green colony y: yellow colony
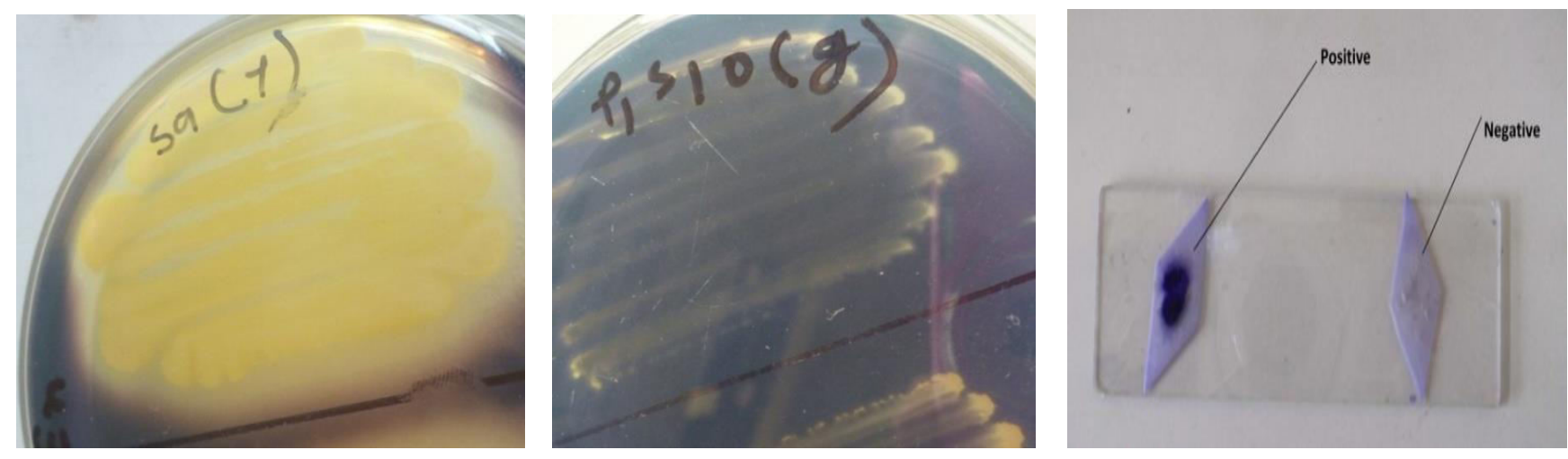

Fig 4: Starch hydrolysis test shows positive (left) and shows negative result (middle) and Oxidase test represented positive result (right). 
Table 6: Gelatin hydrolysis, starch hydrolysis by representative test extracts:

\begin{tabular}{|c|c|c|}
\hline Isolate name & Gelatin hydrolysis & Starch hydrolysis \\
\hline $\mathbf{1}$ & - & - \\
$\mathbf{3}$ & + & - \\
$\mathbf{4}$ & + & + \\
$\mathbf{5}$ & - & - \\
$\mathbf{6}$ & + & - \\
$\mathbf{7}$ & + & + \\
$\mathbf{8}$ & - & - \\
$\mathbf{9}$ & + & + \\
$\mathbf{1 0}$ & + & + \\
\hline
\end{tabular}

Symbol: $+=$ positive, $-=$ negative

Table 7: Sugar fermentation reaction profile of the extracts with interpretation.

\begin{tabular}{|c|c|c|c|c|c|}
\begin{tabular}{c|c|c|c|} 
Sample \\
No
\end{tabular} & DX & L & S & MN & Interpretation \\
$\mathbf{1}$ & + & - & - & + & \\
$\mathbf{2}$ & + & - & - & + & \\
$\mathbf{3}$ & + & - & + & + & Vibrio spp \\
$\mathbf{4}$ & + & - & + & + & \\
$\mathbf{5}$ & + & - & - & + & \\
$\mathbf{6}$ & + & - & + & + & \\
$\mathbf{7}$ & + & - & + & + & \\
$\mathbf{8}$ & + & - & + & + & \\
$\mathbf{9}$ & + & - & - & + & \\
$\mathbf{1 0}$ & + & - & - & + & \\
\hline
\end{tabular}

Symbols: DX=Dextrose, L =Lactose, S=Sucrose, MN=Mannitol,
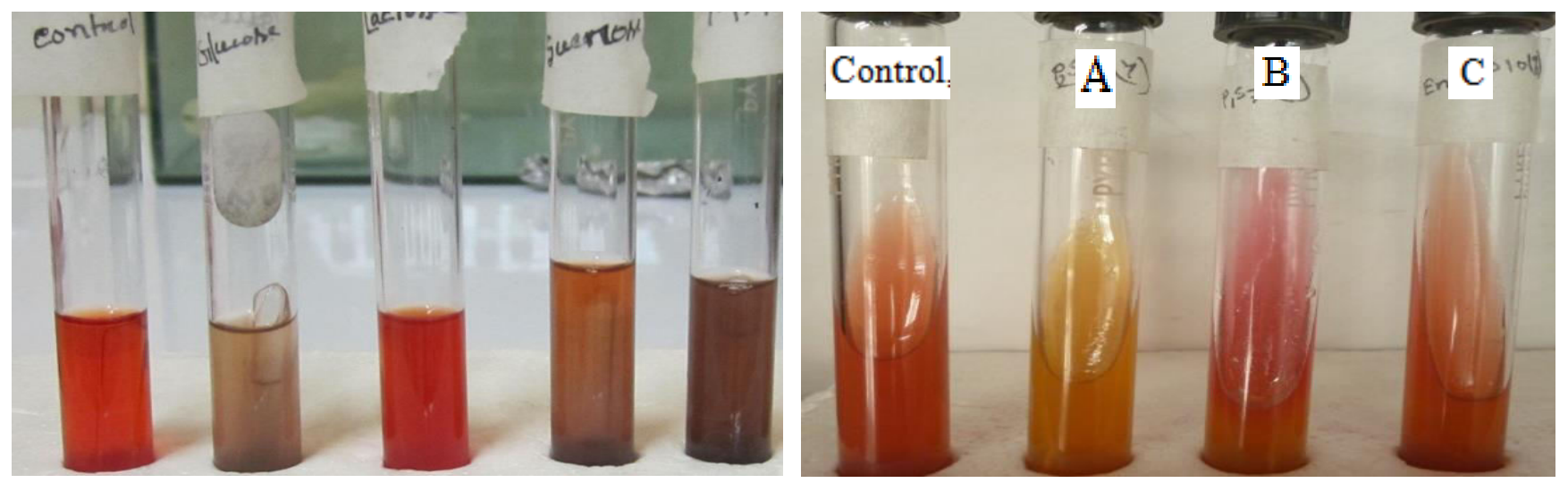

Fig 5: Result of sugar fermentation tests Vibrio spp fermented dextrose, sucrose and mannitol produce acid and gas but did not ferment lactose (left); KIA test (right, Control, A, B showing positive result and C showing negative result). 

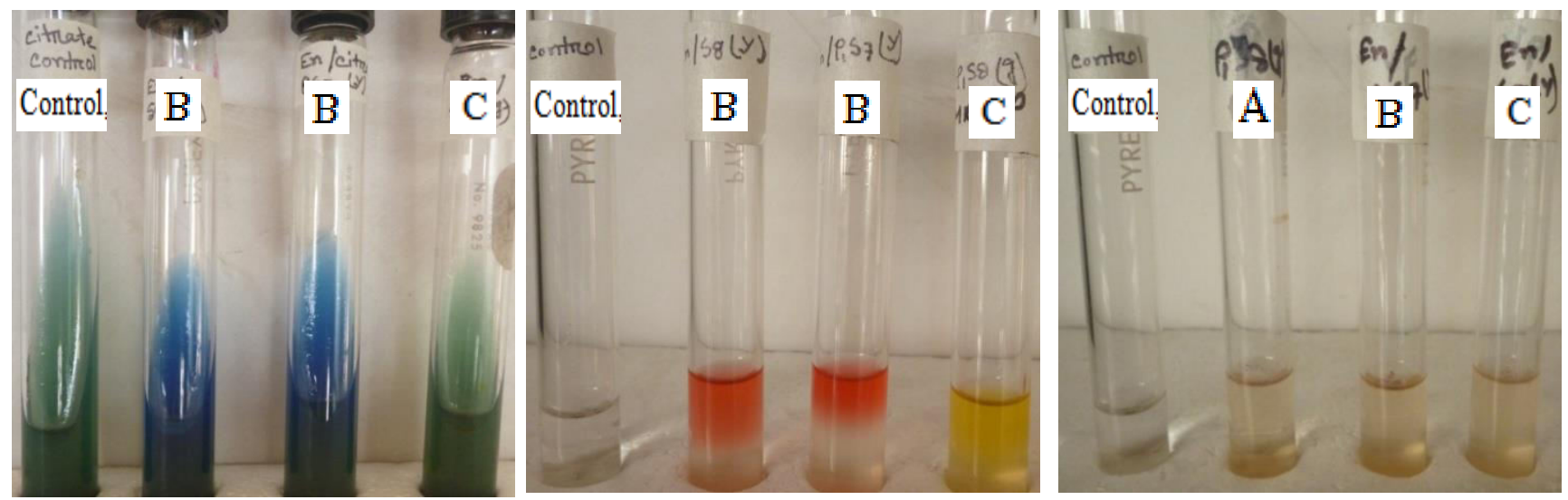

Fig 6: Citrate test (Left, Control; B. showing positive and C. showing negative result); MR test (Middle, C. shows MR negative and B. shows positive result); and Result of Voges- Proskauer test represented no color change (right).

Table 8: Result of starch, citrate, and indole, KIA, MR, VP without Enrichment.

\begin{tabular}{|c|c|c|c|c|c|c|}
\hline Isolate name & $\begin{array}{c}\text { Starch } \\
\text { hydrolysis }\end{array}$ & $\begin{array}{c}\text { Citrate } \\
\text { utilization test }\end{array}$ & Indole & KIA & MR & VP \\
\hline 5 & - & - & - & + & + & _- \\
\hline 6 & + & - & - & + & + & 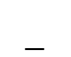 \\
\hline 7 & _- & - & - & + & + & - \\
\hline 8 & + & + & - & + & + & - \\
\hline 9 & + & + & + & + & + & - \\
\hline 10 & - & - & + & - & + & - \\
\hline
\end{tabular}

Symbols: + : positive, - : Negative

Table 9: Antibiogram profile against test extract of Vibrio spp.

\begin{tabular}{|c|c|c|c|c|c|c|c|c|c|c|}
\hline \multirow[t]{2}{*}{ Sample name } & \multicolumn{10}{|c|}{ Antibiotic name } \\
\hline & $\mathrm{E}$ & $\mathrm{TE}$ & $\mathrm{C}$ & GEN & $\mathrm{P}$ & $\mathrm{CN}$ & VA & $\mathrm{F}$ & SXT & CIP \\
\hline 1 & $\mathrm{R}$ & $\mathrm{S}$ & M & $\mathrm{R}$ & $\mathrm{R}$ & $\mathrm{R}$ & $A^{R}$ & S & $\mathrm{S}$ & $\mathrm{R}$ \\
\hline 2 & $\mathrm{R}$ & S & $\mathrm{R}$ & $\mathrm{R}$ & $\mathrm{R}$ & $\mathrm{R}$ & $\mathrm{R}$ & M & S & $\mathrm{R}$ \\
\hline 3 & $\mathrm{R}$ & M & S & $\mathrm{R}$ & $\mathrm{R}$ & $\mathrm{R}$ & M & $\mathrm{S}$ & M & $\mathrm{S}$ \\
\hline 4 & $\mathrm{R}$ & $\mathrm{S}$ & S & $\mathrm{S}$ & $\mathrm{R}$ & $\mathrm{R}$ & $\mathrm{R}$ & $S$ & $\mathrm{~S}$ & $\mathrm{~S}$ \\
\hline 5 & $\mathrm{R}$ & $\mathrm{R}$ & S & $\mathrm{S}$ & $\mathrm{R}$ & $\mathrm{R}$ & $\mathrm{R}$ & M & S & S \\
\hline 6 & $\mathrm{R}$ & $\mathrm{R}$ & $\mathrm{R}$ & S & $\mathrm{R}$ & $\mathrm{R}$ & $\mathrm{R}$ & M & S & M \\
\hline 7 & $\mathrm{R}$ & $\mathrm{R}$ & S & S & $\mathrm{R}$ & $\mathrm{R}$ & $\mathrm{R}$ & $\mathrm{S}$ & S & $\mathrm{S}$ \\
\hline 8 & M & M & S & S & $\mathrm{R}$ & $\mathrm{R}$ & $\mathrm{R}$ & S & S & $\mathrm{S}$ \\
\hline 9 & $\mathrm{R}$ & M & S & S & $\mathrm{R}$ & $\mathrm{R}$ & M & S & S & M \\
\hline 10 & $\mathrm{R}$ & M & $S$ & $S$ & $\mathrm{R}$ & $\mathrm{R}$ & $\mathrm{R}$ & M & $\mathrm{S}$ & $\mathrm{S}$ \\
\hline
\end{tabular}

Key to the abbreviation of the antibiotics: E-Erythromycin, TE-Tetracycline, C-Chloramphenicol, GENGentamycin, P-Penicillin, CN-Cephalexin, VA-Vancomycin, F-Nitrofurantoin, CIP-Ciprofloxacin, SXTSulfamethoxazole, R-Resistant, and S-Sensitive. 

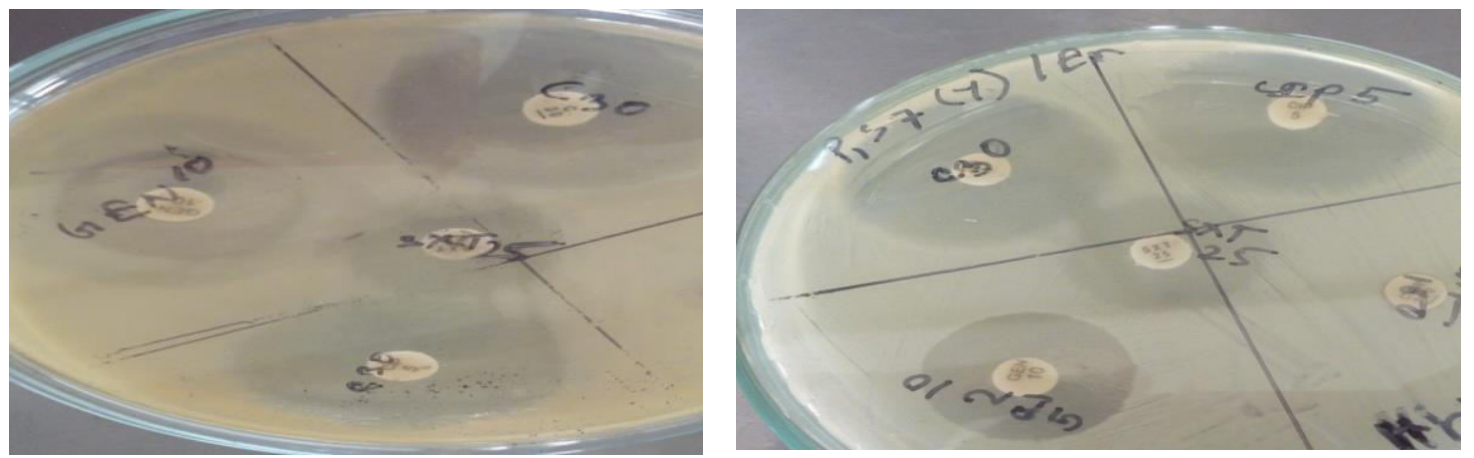

Fig 7: Result of antibiotic sensitivity test.

We investigate the antibiotic susceptibility; Vibrio species were extracted and identified from the sample of water. Among the 15 extracts, 9 extracts represented green and 6 extracts represented yellow colony. Susceptibility of these Vibrio species was assayed by the disc diffusion approach against 10 antibiotics. Among the 9 extracts, 6 extracts represented sensitive against Chloramphenicol, 9 extracts represented highly sensitive against Sulphamethoxazole, Gentamicin,
Nitrofurantoin, and 5 extracts sensitive against ciprofloxacin.

Among the 9 extracts were resistant against Erythromycin, Penicillin, Cephalexin, Vancomycin and 4 extracts resistant against Tetracycline. Vibrio species extracted in this study represented good susceptibility to most of the antimicrobial agents that are commercially available for the treatment of causing disease.

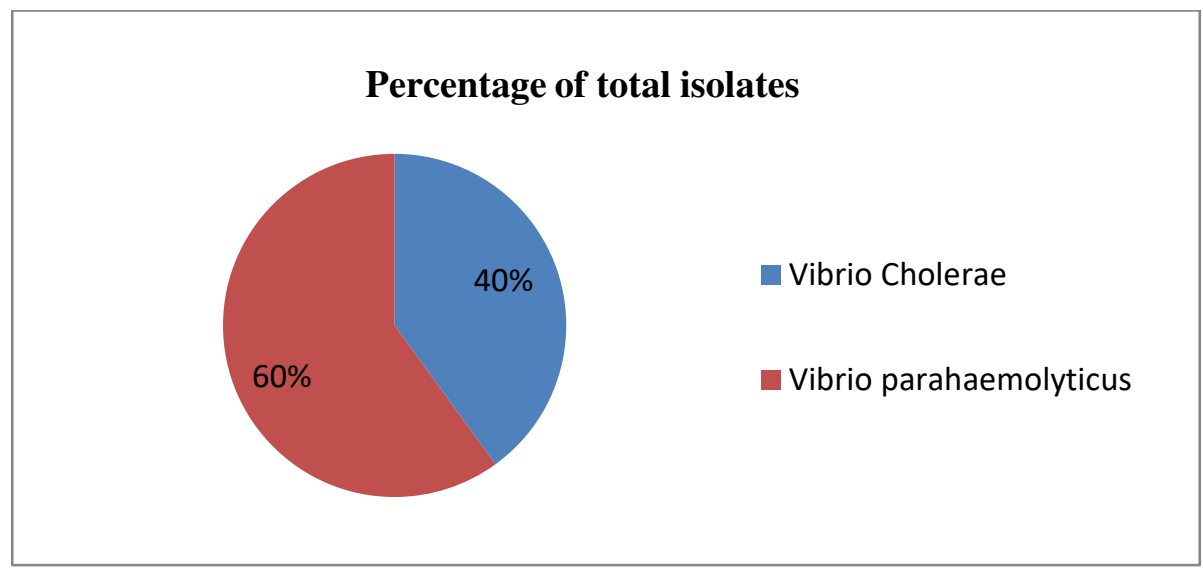

Fig 8: Graphical representation of Total extracts.

\section{CONCLUSIONS}

The present study focuses on the incidence of Vibrio spp in water bodies which are used by people in surroundings for their daily needs. For all living organisms, water is the most vital and significant matter for survival. Despite modern techniques for disinfection, sanitation, and water purification, waterborne diseases still threaten human health. Studies represented that ingestion of water contaminated with Vibrio spp like $V$. cholerae can create serious symptoms including diarrhea, enteritis, and even death, leading to high economic losses. These bacteria are found almost everywhere. Humans, animals, and sewage can be sources of these bacteria. Contaminated water plays a significant role in the transmission of bacteria to human body. The primary goal of this work the separation and identification of Vibrio spp from a different region of water such as tap water, pond water, river, and sewage water and was 
conducted to determine the separation and identification of gram-negative Vibrio spp organisms by cultural study, staining procedure and different type of biochemical test. The purpose of the study was to extract and identify the presence of Vibrio spp in the water bodies in different areas of Bangladesh as well as determine the pattern of antibiotic resistance. Finally, more work should be done on the molecular level to confirm extracts as they are not being extracted using the cultural approach.

\section{ACKNOWLEDGEMENTS}

The authors express their deep sense of gratitude to the authority of NIP Chemicals \& Pharmaceuticals Ltd and Stamford University Bangladesh. Many thanks, to the co-workers supporting for successful completion of the research work.

\section{CONFLICTS OF INTEREST}

The authors declared no potentially conflicts of the interest with respect to the research, authorship and publication of this article.

\section{REFERENCES}

1. Azila, A., Ramli, R., Ridzuan, M.S.M., Murni, M., Hashim, S., Sudirwan, F., Siti-Zahrah, A., Zamri-Saad, M. and Amal, M.N.A. (2017) The presence of Vibrionaceae, Betanodavirus and Iridovirus in marine cage-cultured fish: role of fish size, water physicochemical parameters and relationships among the pathogens. Aquacult Rep 7, 57-65

2. AUSTIN B., ZHANG X.H. (2006) Under the microscope Vibrio harveyi: a significant pathogen of marine vertebrates and invertebrates. Lett. Appl. Microbiol. 43, 119-124

3. Cho, S.-H., Shin, H.-H., Choi, Y.-H., Park, M.S., \& Lee, B. K. (2008) Enteric bacteria isolated from acute diarrheal patients in the Republic of Korea between the year 2004 and 2006. J. Microbiol 46, 325-330

https://doi.org/10.1007/s12275-008-0015-4

4. Duran GM and Marshall DL (2005) Ready-toeat shrimp as an international vehicle of antibiotic-resistant bacteria. J. of Food Protection 68: 2395-2401
5. Forsythe, S. J. (2000) Food safety assurance in the EU. Nottingham Trent University, Nottingham, UK

6. Gomez-Gil, B., Thompson, C.C., Matsumura, Y., Thompson, F. and Sawabe, T. (2014) Family Vibrionaceae. In The Prokaryotes- Gammaproteobacteria, ed. Rosenberg, E.F., DeLong, E.F., Lory, S., Stackebrandt, E., and Thompson, F. pp. 659-747. Berlin Heidelberg: SpringerVerlag.

7. Guglielmetti E, Korhonen JM, Heikkinen J, Morelli L, and Von Wright A. (2009) Transfer of plasmid-mediated resistance to tetracycline in pathogenic bacteria from fish and aquaculture environments. FEMS Microbiology Letters 293: 28-34

8. Haenen, O.L.M., Fouz Rodríguez, B., Amaro González, C., Hellstrom, A. and Dalsgaard, I. (2014) Vibriosis in aquaculture. 16th EAFP Conference, Finland, $4^{\text {th }}$ September 2013. B Eur Assoc Fish Pat. 34(4), 138-147

9. Ina-Salwany, M.Y., Al-saari, N., Mohamad, A., Fathin-Amirah, M., Mohd, A., Amal, M.N.A., Kasai, H., Mino, S., Sawabe, T. and Zamri-Saad, M. (2018) Vibriosis in fish: a review on disease development and prevention. J Aquat Anim Health 31: 2-22. https://doi.org/10.1002/aah.10045

10. Jayasree L, Janakiram P, Madhavi R. (2006) Characterization of Vibrio spp. Associated with Diseased Shrimp from Culture Ponds of Andhra Pradesh (India). J. of the World Aquaculture Society 37, 523

11. Letchumanan, V., Pusparajah, P., Lee, L.H. and Chan, K.G. (2015) Occurrence and antibiotic resistance of Vibrio parahaemolyticus from shellfish in Selangor, Malaysia. Front Microbiol. 6, 1417

12. Li, M. H.; Robinson, E. H. (2006) Use of cottonseed meal in aquatic animal diets: a review. North Am. J. Aquacult. 68(1): 14-22

13. Khuntia CP, Das BK, Samantaray BR, Samal SK, and Mishra BK (2008) Characterization and pathogenicity studies of Vibrio parahaemolyticus extracted from diseased 
freshwater prawn, Macrobrachium rosenbergii (de Man). Aquacult Res. 39(3): 301-10

14. Mala E, Oberoi A, and Alexander VS (2014) Vibrio isolate from cases of acute diarrhea and their antimicrobial susceptibility pattern in a tertiary care hospital. International J. of Basic and Applied Sciences 3: 35-37

15. Özer, S., Aslan, G., Tezcan, S., Bulduklu, M. S., and Emekdas, G. (2008) Genetic heterogeneity and antibiotic susceptibility of Vibrio alginolyticus strains isolated from Trachurus trachurus L. Turkish J. of Veterinary and Animal Sciences 32(2), 107-112

16. Parveen, S., Hettiarachchi, K.A., Bowers, J.C., Jones, J.L., Tamplin, M.L., McKay, R., Beatty, W., Brohawn, K., Dasilva, L.V., \& DePaola, A. (2008) Seasonal distribution of total and pathogenic Vibrio parahaemolyticus in Chesapeake Bay oysters and waters. Int. J. Food Microbiol. 128, 354-361

https://doi.org/10.1016/j.ijfoodmicro.2008.09.019

17. Rahman MA, Haque A, Ahmad T, Mahmud S, Barman NC, Uddin ME, and Ahmed R. (2019) Isolation, identification and antibiotic sensitivity pattern of Salmonella spp from locally isolated egg samples. Am. J. Pure Appl. Sci, 1(1), 1-11 https://doi.org/10.34104/ajpab.019.019111

18. Raissy M, Khamesipour F, Rahimi E, and Khodadoostan A (2014) Occurrence of Vibrio, Aeromonas hydrophila, E. coli and Campylobacter in crayfish (Astacus leptodactylus) from Iran. Iranian J. of Fisheries Sciences 13(4): 944- 954

19. Shaw KS, Rosenberg GRE, He X, Jacobs JM, Crump BC, and Sapkota AR (2014) Antimicrobial susceptibility of Vibrio vulnificus and
Vibrio parahaemolyticus recovered from recreational and commercial areas of Cheaspeake Bay and Maryland coastal bay. PLoS ONE 9: e89616

20. Tan, C. W., Malcolm, T. T. H., Kuan, C. H., Thung, T. Y., Radu, S. (2017) Prevalence and antimicrobial susceptibility of Vibrio parahaemolyticus isolated from short mackerels (Rastrelliger brachysoma) in Malaysia. Frontiers in Microbiol. 8: 1-9 https://doi.org/10.3389/fmicb.2017.01087

21. Thompson FL, Iida T, and Swings J. (2004) Biodiversity of vibrios. Microbiol and Molecular Biology Reviews 68(3): 403-431

22. Turner, J.W., Paranjpye, R.N., Landis, E.D., Biryukov, S.V., Nilsson, W.B., \& Strom, M.S. (2013) Population Structure of Clinical and Environmental Vibrio parahaemolyticus from the Pacific Northwest Coast of the United States. PLoS One, 8, e55726 https://doi.org/10.1371/journal.pone.0055726

23. Yang, Z.Q., X.A. Jiao, X.H. Zhou, G.X. Cao, R.X. Gu.2008. Isolation and molecular characterization of Vibrio parahaemolyticus from fresh, low-temperature preserved, dried and salted seafood products in two coastal areas of eastern China. International J. of Food Microbiol. 125: 279-285

24. Zhou, J., Fang, W., Yang, X., Zhou, S., Hu, L., Li, X., Qi, X., Su, H. and Xie, L. 2012. A nonluminescent and highly virulent Vibrio harveyi strain is associated with "Bacterial white tail disease of Litopenaeus vannamei shrimp. PLoS ONE 7: e29961. https://doi.org/10.1371/journal.pone.0029961

Citation: Sarker MKD, Ahammed T, Sahabuddin M, Akter P, Haque A, Hossain MR, Mosaib MG, Islam MR, Mondol GC, and Alam MF. (2019). Antibiotic resistance analysis of Vibrio spp isolated from different types of water sources of Bangladesh and their characterization. Eur. J. Med. Health Sci., 1(4), 19-29. https://doi.org/10.34104/ejmhs.01929 (C) @ 